$\S$ 


\title{
Book of Remembrance
}

\section{The German, Austrian and Czechoslovakian Jews deported to the Baltic States}

\author{
Compiled \\ by
}

Wolfgang Scheffler and Diana Schulle

\author{
Edited \\ by "Volksbund Deutsche Kriegsgräberfürsorge e.V." \\ and "Riga-Komitee der deutschen Städte" \\ in cooperation with the "Stiftung Neue Synagoge Berlin - Centrum Judaicum" \\ and the memorial "Haus der Wannsee-Konferenz"
}

Volume I

K·G·Saur München 2003 


\title{
Buch der Erinnerung
}

\author{
Die ins Baltikum deportierten deutschen, \\ österreichischen und tschechoslowakischen Juden
}

\author{
Bearbeitet \\ von \\ Wolfgang Scheffler und Diana Schulle
}

Herausgegeben

vom „Volksbund Deutsche Kriegsgräberfürsorge e.V“

und dem „Riga-Komitee der deutschen Städte“

gemeinsam mit der Stiftung „Neue Synagoge Berlin - Centrum Judaicum“

und der Gedenkstätte „Haus der Wannsee-Konferenz“

Band I

K·G·Saur München 2003 


\section{Das Projekt wurde gefördert von \\ der „Alfried Krupp von Bohlen und Halbach - Stiftung“, der „Initiative Riga“, Wien und der Stadt Wien}

Bibliografische Information Der Deutschen Bibliothek

Die Deutsche Bibliothek verzeichnet diese Publikation in der Deutschen Nationalbibliografie; detaillierte bibliografische Daten sind im Internet über $h t t p: / / d n b . d d b . d e$ abrufbar.

Übersetzung ins Englische: Caroline Gay, Bath

๑)

Gedruckt auf säurefreiem Papier

(C) 2003 by K. G. Saur Verlag GmbH, München

Printed in Germany

Alle Rechte vorbehalten.

Das Werk ist in allen seinen Teilen urheberrechtlich geschützt.

Jede Verwertung ist ohne Zustimmung des Verlages unzulässig.

Das gilt insbesondere für Vervielfältigungen, Übersetzungen, Mikroverfilmungen

und die Einspeicherung in und Verarbeitung durch elektronische Systeme.

Satz: SRZ Satz-Rechen-Zentrum Hartmann + Heenemann GmbH \& Co. KG, Berlin

Druck/Bindung: Strauss Offsetdruck GmbH, Mörlenbach

ISBN 3-598- I I6I8-7 (2 Bände) 